\title{
Fabrication of 3D-Printed Interpenetrating Hydrogel Scaffolds for Promoting Chondrogenic Differentiation
}

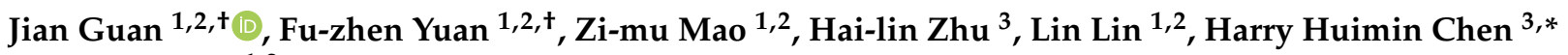 \\ and Jia-kuo Yu 1,2,*
}

check for updates

Citation: Guan, J.; Yuan, F.-Z.; Mao, Z.-m.; Zhu, H.-l.; Lin, L.; Chen, H.H.; Yu, J.-k. Fabrication of 3D-Printed Interpenetrating Hydrogel Scaffolds for Promoting Chondrogenic Differentiation. Polymers 2021, 13, 2146. https://doi.org/10.3390/ polym 13132146

Academic Editors: Vahid Serpooshan, Murat Guvendiren and Dimitrios Bikiaris

Received: 8 June 2021

Accepted: 27 June 2021

Published: 29 June 2021

Publisher's Note: MDPI stays neutral with regard to jurisdictional claims in published maps and institutional affiliations.

Copyright: (c) 2021 by the authors. Licensee MDPI, Basel, Switzerland. This article is an open access article distributed under the terms and conditions of the Creative Commons Attribution (CC BY) license (https:/ / creativecommons.org/licenses/by/ $4.0 /)$.
1 Beijing Key Laboratory of Sports Injuries, Sports Medicine Department, Peking University Third Hospital,

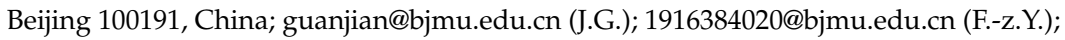
maozimu@yeah.net (Z.-m.M.); Simon.lin2003@163.com (L.L.)

2 Institute of Sports Medicine of Peking University, Beijing 100191, China

3 SinoBioPrint (Shanghai) Biotech Ltd., 23 Building, 1188 Lianhang Road, Minhang District, Shanghai 201112, China; hailin.zhu@stemeasy.com

* Correspondence: Huimin.chen@sinobioprint.com (H.H.C.); yujiakuo@126.com (J.-k.Y.)

+ These authors contributed equally to this study.

\begin{abstract}
The limited self-healing ability of cartilage necessitates the application of alternative tissue engineering strategies for repairing the damaged tissue and restoring its normal function. Compared to conventional tissue engineering strategies, three-dimensional (3D) printing offers a greater potential for developing tissue-engineered scaffolds. Herein, we prepared a novel photocrosslinked printable cartilage ink comprising of polyethylene glycol diacrylate (PEGDA), gelatin methacryloyl (GelMA), and chondroitin sulfate methacrylate (CSMA). The PEGDA-GelMA-CSMA scaffolds possessed favorable compressive elastic modulus and degradation rate. In vitro experiments showed good adhesion, proliferation, and F-actin and chondrogenic differentiation of bone marrow mesenchymal stem cells (BMSCs) on the scaffolds. When the CSMA concentration was increased, the compressive elastic modulus, GAG production, and expression of F-actin and cartilage-specific genes (COL2, ACAN, SOX9, PRG4) were significantly improved while the osteogenic marker genes of COL1 and ALP were decreased. The findings of the study indicate that the 3D-printed PEGDAGelMA-CSMA scaffolds possessed not only adequate mechanical strength but also maintained a suitable 3D microenvironment for differentiation, proliferation, and extracellular matrix production of BMSCs, which suggested this customizable 3D-printed PEGDA-GelMA-CSMA scaffold may have great potential for cartilage repair and regeneration in vivo.
\end{abstract}

Keywords: 3D printing; hydrogel scaffold; cartilage repair; GelMA; CSMA

\section{Introduction}

The degeneration of articular cartilage due to trauma, osteoarthritis, and aging is a common joint disorder worldwide [1]. It is reported that the limited intrinsic self-healing capacity was noted on cartilage because of its avascular nature [2]. Although some clinical treatments, such as autologous chondrocyte implantation mosaicplasty and microfracture, are available for articular cartilage repair [3], such techniques are limited in offering long-term correction of cartilage pathologies [4], thus necessitating the development of alternative strategies. The development of synthetic scaffolds via tissue engineering approaches can be a promising strategy for cartilage regeneration and repair [5,6].

The application of hydrogels is receiving increasing consideration in biomedical fields, including drug delivery, tissue engineering, and regenerative medicine. Additionally, the hydrogels possess similar morphology to the natural extracellular matrix (ECM), offering mimetic conditions for cell culture [7,8]. Three-dimensional (3D) printed scaffolds have already been proven as better choices for cartilage tissue engineering than those conventional techniques such as freeze-drying [9]. 3D printing using computer-aided design 
(CAD) has the potential to precisely regulate the uniform morphology and interconnected porous structure of bioinspired scaffolds, which provides the base for fabricating complex, customizable, and artificial constructs for cartilage regeneration [10]. Fused deposition modeling (FDM) is an additive manufacturing technique used for prototyping, production, and modeling applications. FDM enables the rapid fabrication of highly interconnected pore geometries and channel sizes [11,12]. Moreover, it is a cost-effective approach to print high-resolution constructs compared to other 3D printing techniques, which are often overwhelmed by the viscosity of bio-ink.

Gelatin methacrylate (GelMA) is a major component of ECM derived from the hydrolysis of collagen, which contains matrix metalloproteinase sequences and arginine-glycineaspartic (RGD) acids for promoting cell adhesion and proliferation [13]. Chondroitin sulfate (CS), a natural polymer, is predominantly part of the aggrecan. A previous study suggested that CS mediated several biological mechanisms involved in developing resistance to compressive loading [14]. It was found that CS-mediated expression of chondrocytes phenotype was useful for guiding the tissue repair for regenerative medicine applications [15]. Meanwhile, another photocrosslinkable biomaterial of poly (ethylene glycol) diacrylate (PEGDA) was blended with GelMA and chondroitin sulfate-methacrylamide (CSMA) for improving the printability and strength of the scaffolds [16]. The aforementioned three kinds of photocurable biomaterials can be well-polymerized under $405 \mathrm{~nm}$ blue light [17-19].

In the present study, a novel ink comprising of PEGDA, GelMA, and CSMA was prepared to print 3D scaffolds for cartilage tissue regeneration. We used the conventional FDM to print a poly (lactic acid) (PLA) porous scaffold as a mold, followed by mixing gel precursors and pouring it into the mold, leaving the liquid level a little above those. After exposure to $405 \mathrm{~nm}$ blue light for $30 \mathrm{~s}$ and removal of pre-mold, high-resolution 3D-printed PEGDA-GelMA-CSMA hydrogel scaffolds were obtained with uniform interconnected pores. The 3D-printed interpenetrating polymer network (IPN) hydrogel scaffold was fabricated for promoting the chondrogenic differentiation of BMSCs. BMSCs were seeded on different 3D-printed PEGDA-GelMA-CSMA scaffolds, and the relevant physicochemical and biological characteristics of the 3D scaffolds were investigated. Additionally, the expression of cartilage-specific marker genes, main osteogenic marker genes, and secretion of glycosaminoglycan (GAG) were also determined for evaluating the chondrogenic differentiation of BMSCs on the 3D scaffolds in vitro. These PEGDA-GelMA-CSMA hydrogel scaffolds mimicked ECM composition and demonstrated the biomechanical properties of cartilage tissue by providing an appropriate microenvironment for exogenous seeded cells or endogenic BMSCs. We believe this study will provide a platform for designing the 3D-printed hydrogel scaffolds as a promising one-step approach by combining the endogenic and exogenous BMSCs for cartilage repair.

\section{Materials and Methods}

\subsection{Materials}

Gelatin methacrylate (GelMA), chondroitin sulfate-methacrylamide (CSMA) and the photoinitiator, lithium phenyl-2,4,6-trimenthylbenzoylphosphinate (LAP) were obtained from SinoBioPrint (Shanghai, China) Biotech Ltd (Shanghai, China).

\subsection{Designing of Mold}

A 3D CAD model of $45 \times 45 \mathrm{~mm}^{2}$ grid-network structure ( $3 \mathrm{~mm}$ in height) was designed via CREO (STL file) and Repetier-Host (print parameters) soft wares (Hot-World $\mathrm{GmbH} \& \mathrm{Co}$. KG, Willich, Germany). We chose a common thermoplastic filament PLA for FDM printing [12]. The 3D printing system used in this study was a commercial desktop printer (JGAURORA, $305 \mathrm{~mm} \times 305 \mathrm{~mm} \times 320 \mathrm{~mm}$, Shenzhen, China). The printing parameters were set as speed $60 \mathrm{~mm} / \mathrm{s}$, nozzle temperature $210{ }^{\circ} \mathrm{C}$, platform temperature $60^{\circ} \mathrm{C}$, FDM printer nozzle diameter $250 \mu \mathrm{m}$, and grid model infill ratio $50 \%$. 


\subsection{Synthesis of Photo-Polymerizable Mixture Gel Precursor}

GelMA and CSMA were synthesized according to previous studies [20,21]. PEGDA $\left(\mathrm{M}_{\mathrm{n}}=700\right.$, Sigma-Aldrich, St. Louis, MA, USA $)$ was mixed with different amounts of GelMA and CSMA. The photoinitiator of lithium phenyl-2,4,6-trimethylbenzoylphosphinate (LAP) was used to form the photo-polymerizable mixture gel precursor by dissolving in deionized water at $60^{\circ} \mathrm{C}$.

\subsection{Preparation of Photocurable IPN Hydrogel Porous Scaffolds Using 3D Composite-Printing and Lyophilization}

The aforementioned gel precursors were poured into the mold, leaving the liquid level a little above that, and then the composites were exposed to a wavelength of $405 \mathrm{~nm}$ blue light laser source $\left(30 \mathrm{~mW} / \mathrm{cm}^{2}\right)$ for $30 \mathrm{~s}$ to form photocurable hydrogel (irreversible). The composites were soaked in the dichloromethane solution for several hours, during the process, the PLA mold would be dissolute gradually, then remove the waste liquid, and soaked in deionized water for a few minutes. Finally, the remaining reinforced photocurable IPN hydrogel porous scaffolds were cut into different sizes by specific corneal trephine. After preparation, the scaffolds were frozen at $-20^{\circ} \mathrm{C}$ for $2 \mathrm{~h}$ and then lyophilized for $12 \mathrm{~h}$. The scaffolds were sterilized with ethylene oxide and the experiment was started.

\subsection{Characterization of Macromers and 3D-Printed Hydrogel Scaffolds}

Gelatin, GelMA, CS, and CSMA were characterized and analyzed by ${ }^{1} \mathrm{H}$ NMR (Bruker $400 \mathrm{MHz}$ NMR spectrometer). The morphology of the 3D printing scaffold was observed through an optical microscope and scanning electron microscope (SEM). The samples were plated about $8 \mathrm{~nm}$ in a high vacuum gold sputter coater and observed under a Phenom Pharos SEM (Holland). The universal testing machine with $6 \mathrm{~mm} / \mathrm{min}$ as a crosshead speed was applied to test the mechanical properties of 3D scaffolds. Briefly, the samples were cut into $10 \mathrm{~mm}$ diameter and $3 \mathrm{~mm}$ thick disks. The stress-strain curve was used for calculating the compressive elastic modulus. All analyses were performed in triplicate.

\subsection{In Vitro Degradation}

The degradation behavior of 3D-printed PEGDA-GelMA-CSMA hydrogel scaffolds was evaluated by recording the weight loss of scaffolds in proteinase $\mathrm{K}$ solution over 21 days. We recorded the initial weight of lyophilized PEGDA-GelMA-CSMA hydrogel scaffolds $\left(W_{0}\right)$. The scaffolds were incubated in proteinase $\mathrm{K}$ for 1, 4, 7, 14, and 21 days at $37^{\circ} \mathrm{C}$. After incubation, the scaffolds were lyophilized and weighed again $\left(W_{\mathrm{t}}\right)$. The degradation ratio was calculated as the following:

Degradation ratio $(\%)=\left(W_{0}-W_{\mathrm{t}}\right) / W_{0} \times 100 \%$

\subsection{Isolation and Culturing of BMSCs}

The Animal Care and Use Committee of Peking University Third Hospital approved all the protocols of animal experiments that were implemented following the Guide for the Care and Use of Laboratory Animals. BMSCs were isolated following the protocol reported in a previous study [3]. At a confluence of $80-90 \%$, BMSCs were trypsinized with $0.25 \%$ trypsin $/ 0.1 \%$ ethylene diamine tetra-acetic acid for subculture at $1: 2$. BMSCs were cultured in a-MEM with penicillin $(100 \mathrm{U} / \mathrm{mL})$, streptomycin $(100 \mathrm{U} / \mathrm{mL})$, and $15 \%$ fetal bovine serum. In the chondrogenic differentiation study, the BMCs-seeded constructs were cultured in a chondrogenic differentiation medium (CTCC-Y002; CTCC Biosciences Inc., Jiangyin, China) after three days in the growth medium.

\subsection{Cell Seeding on 3D Hydrogel Scaffolds}

A $10 \mu \mathrm{L}$ of BMSCs suspension at a density of $1 \times 10^{7}$ cells $/ \mathrm{mL}$ was seeded on 3Dprinted hydrogel scaffolds of $5 \mathrm{~mm}$ diameter and $3 \mathrm{~mm}$ thickness by centrifugation [22]. The cell-scaffold composites were incubated for $1 \mathrm{~h}$ to allow the adhesion of cells, and then 
the cell-seeded hydrogel scaffolds were transferred to 96-well plates for suspension culture, followed by the addition of $150 \mu \mathrm{L}$ of fresh growth medium.

\subsection{Cytocompatibility}

Cell proliferation on scaffolds was detected by cell counting kit-8 (CCK-8; Dojindo Laboratories, Kumamoto, Japan). The original culture medium was replaced with $90 \mu \mathrm{L}$ of fresh culture medium and $10 \mu \mathrm{L}$ CCK-8 reagent after incubation for 1, 3, 5, and 7 days. The absorbance was detected at $450 \mathrm{~nm}$ every $2 \mathrm{~h}$ using a microplate reader (Thermo, Waltham, MA, USA).

\subsection{Live/Dead Staining}

To visualize cell growth and distribution on hydrogel scaffolds, a Live/Dead staining assay was performed by the Viability/Cytotoxicity Kit (Invitrogen, Carlsbad, CA, USA). After incubation for 3 days, the cell-hydrogel scaffold composites were washed and immersed in $2 \mathrm{mM}$ of calcein-AM and $4 \mathrm{mM}$ ethidium homodimer- 1 for $2 \mathrm{~h}$ at $37^{\circ} \mathrm{C}$. The fluorescence was observed by using Leica TCS-SP8 confocal laser microscopy (CFLM; Leica, Nussloch, Germany) at an excitation wavelength of 568 or $488 \mathrm{~nm}$. Imaris software 7.4.2 (Bitplane, Oxford, UK) was applied to observe the distribution of BMSCs on the hydrogel scaffolds.

\subsection{Cytoskeleton Staining}

Cytoskeleton staining was performed to observe the morphology of cells on 3D hydrogel scaffolds. After incubation for 5 days, the scaffolds were fixed in $4 \%$ paraformaldehyde for $30 \mathrm{~min}$ after washing. Thereafter, the cells on scaffolds were treated with $0.1 \%$ Triton $\mathrm{X}-100$ solution in PBS and then subjected to F-actin staining and DAPI staining for $1 \mathrm{~h}$ and $5 \mathrm{~min}$, respectively. Finally, the fluorescence microscope (Leica, TCS SP-8, Wetzlar, Germany) was used to observe the samples.

\subsection{RT-PCR Test}

TRIZOL reagent was used to extract the total RNA (Invitrogen, Carlsbad, CA, USA) when the cell-hydrogel composites were incubated for 7 and 14 days. The RNA was reverse transcribed into cDNA by MMLV Reverse Kit, and RT-PCR was conducted by Real-time PCR system (Applied Biosystems, Waltham, MA, USA) with SYBR Green PCR Master Mix (Toyobo, Japan). The value of relative expression of genes was plotted as $2^{-\Delta \Delta C T}$ as reported previously [3]. The primers used for the amplification of target genes were listed in Table 1.

Table 1. Primer sequences are used in this study.

\begin{tabular}{ccc}
\hline Gene & Forward Primers $\left(\mathbf{5}^{\prime} \mathbf{-} \mathbf{3}^{\prime} \mathbf{)}\right.$ & Reverse Primers $^{\left(\mathbf{5}^{\prime} \mathbf{- 3}^{\prime} \mathbf{)}\right.}$ \\
\hline COL1 & ACCCCAGAAACAGACGACAAACAAC & ATGAATGCAACGGCAAAAACAAATC \\
COL2 & GCAGCTGTGTGCAGGAGGGGAAG & TGGCAGTGGCGAGGTCAGTAGGG \\
ACAN & GACTCATTGTTAGAGGACAGCCA & CACTCCCAAAAAGAACTCCAGAT \\
PRG4 & GGCAGGGAATGTGACTGTGATG & TGGGTGAGCGTTTAGTTGTTGA \\
SOX9 & CGGCGGAGGAAGTCGGTGAAGA & AGTGGTGGGTGGGGTGGTGGTG \\
ALP & CCGCAAGTATATGTATCCCAAA & CCCAAGAGGTAGTCCACAGTGT \\
GAPDH & CATCAAGAAGGTGGTGAAGCAGG & AGCATCGAAGGTAGAGGAGTGGG \\
\hline
\end{tabular}

COL1: type I collagen; COL2: type II collagen; ACAN: aggrecan; PRG4: proteoglycan 4 precursors; SOX9: SRY-related high mobility group-box gene 9; ALP: alkaline phosphatase; GAPDH: glyceraldehyde-3-phosphate dehydrogenase.

\subsection{Immunofluorescence Staining}

The production of COL2, SOX9, and ACAN proteins in cell-scaffold constructs was determined by immunofluorescence after three weeks of chondrogenic culturing. The constructs were washed with PBS after fixation with $4 \%$ paraformaldehyde for $30 \mathrm{~min}$. Thereafter, the constructs were incubated with $10 \% \mathrm{FBS}$ for $60 \mathrm{~min}$ at $37^{\circ} \mathrm{C}$ followed by incubation with a solution of primary antibody for anti-collagen type 2 (Abcam, Cambridge, 
UK, ab34712), SOX9 (Abcam, ab185966), and ACAN (Proteintech, Chicago, IL, USA, 13880$1-\mathrm{AP})$ for $24 \mathrm{~h}$ at $4{ }^{\circ} \mathrm{C}$. The nuclei were counter-stained with Hoechst 33258. The proportion of cells expressing the COL2, ACAN, and SOX9 was analyzed by the Image-Pro Plus software (6.0; Media Cybernetics, Rockville, MD, USA).

\subsection{Quantification of DNA, GAG, and COL2 Content}

The COL2 content was tested by an ELISA kit following the manufacturer's instructions (Jianglai bio, Shanghai, China, JL22853). The content of proteoglycan was detected from GAG content by the 1, 9-dimethyl methylene blue (DMMB; Sigma, St. Louis, MO, USA) dye-binding assay. Total GAG was normalized to total DNA content. Thereafter, $20 \mu \mathrm{L}$ of the sample was added to DMMB $(200 \mu \mathrm{L})$ and mixed, and the absorbance was measured at $525 \mathrm{~nm}$. A standard curve was established from chondroitin-6-sulfate, using shark (Sigma, St. Louis, MO, USA). A fluorometric assay was performed to detect DNA content. Specimens were digested in a mixed solution of EDTA (0.5 M), Mcysteine- $\mathrm{HCl}$ (0.05), and papain enzyme $(1 \mathrm{mg} / \mathrm{mL})$ at $70{ }^{\circ} \mathrm{C}$ for $48 \mathrm{~h}$ after weighing. Aliquots of sample digestion were stained with $200 \mu \mathrm{L}$ of Hoechst33258 $(2 \mu \mathrm{g} / \mathrm{mL})$ at $37^{\circ} \mathrm{C}$ for $20 \mathrm{~min}$. The fluorescence intensities were then determined at an excitation wavelength $(360 \mathrm{~nm})$ and an emission wavelength $(460 \mathrm{~nm})$. The DNA content was normalized with a standard curve of calf thymus DNA (Sigma, St. Louis, MI, USA).

\subsection{Statistical Analysis}

The statistical data were expressed as mean \pm standard deviation (SD). One-way analysis of variance (ANOVA) was performed for determining the differences among the groups after testing for homogeneity of variances. $p<0.05$ was considered statistically significant. GraphPad Prism for Windows (GraphPad Software, San Diego, CA, USA) was used to analyze the data.

\section{Results}

\subsection{Preparation and Characterization of GelMA and CSMA}

Figure 1A showed the schematic illustration of preparation and biological evaluation of 3D-printed scaffolds for cartilage tissue regeneration application. ${ }^{1} \mathrm{H}$ NMR spectra analysis was used to testify the synthesis of GelMA and CSMA. The methacrylamide vinyl group signal occurred at 5.5 and $5.7 \mathrm{ppm}$ after adding MA into gelatin (Figure 1B), suggesting the successful grafting of the methyl acryloyl group onto the side chain of gelatin. Similarly, the methacrylamide vinyl group signal at 5.7 and $6.2 \mathrm{ppm}$ indicated the successful preparation of CSMA (Figure 1B). The 3D-printed PEGDA-GelMA-CSMA hydrogel scaffolds with uniformly interconnected pores and high resolution were fabricated with $3 \mathrm{D}$ printing by removing the pre-mold. The hydrogel scaffolds were fabricated via FDM with dimensions of $45 \times 45 \times 3 \mathrm{~mm}^{3}$ by removing the mold and trimmed into cylindrical samples with a 5 -mm diameter corneal trephine. The resultant scaffolds of $3 \mathrm{~mm}$ thickness and $5 \mathrm{~mm}$ diameter were obtained in Figure 1A. A pore size between 100 to $400 \mu \mathrm{m}$ in cartilage repair is better for proliferation, differentiation, and ECM production. Therefore, these 3D-printed scaffolds possessed a smooth surface, uniform pores $(200 \mu \mathrm{m})$, and well-arranged channels (Figure 1C). These observations showed that the 3D-printed scaffolds with the hierarchical structure were successfully prepared via the 3D compositeprinting strategy. 


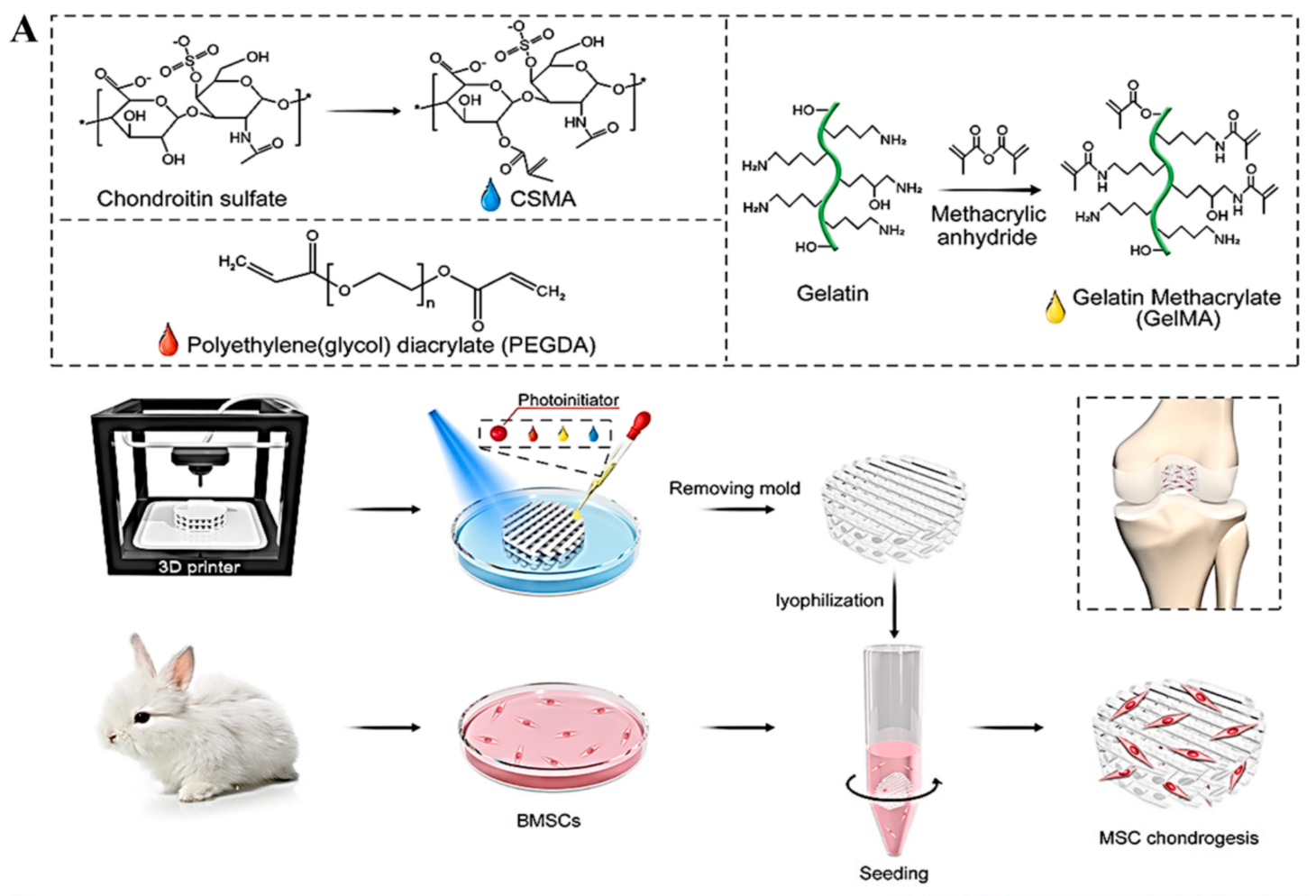

B
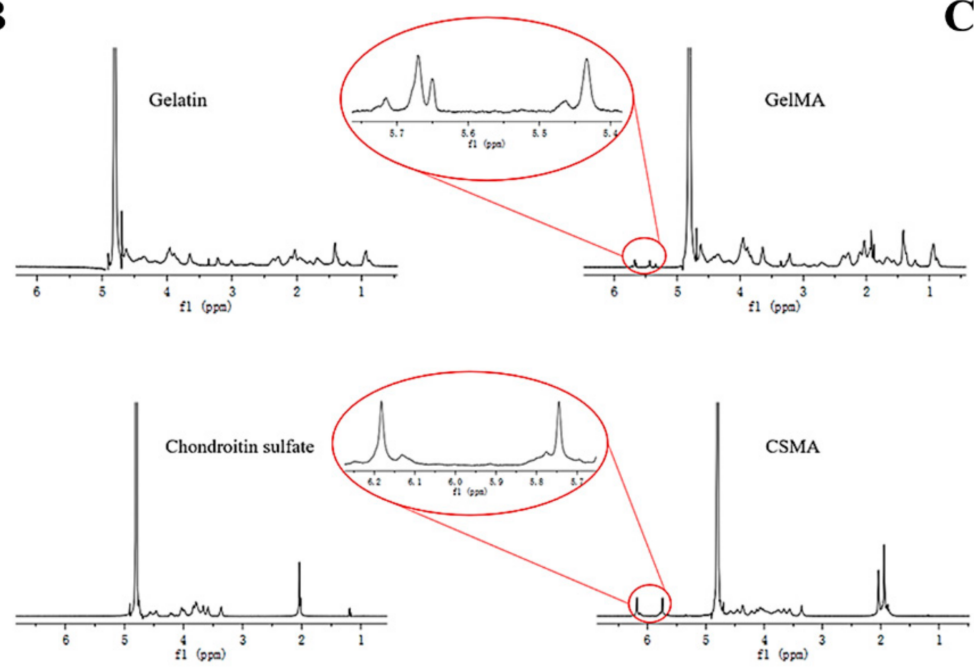

C
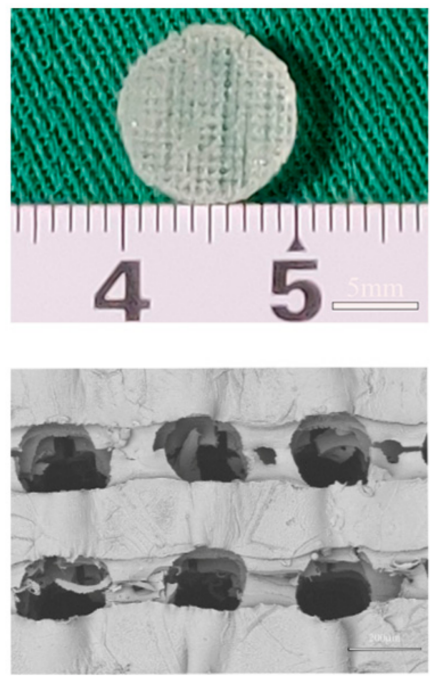

Figure 1. Fabrication of 3D-printed hydrogel scaffolds. (A) Synthetic route of CSMA and GelMA and the schematic illustration of 3D printing of scaffolds as well as the isolation and seeding of cells on the printed scaffolds. (B) ${ }^{1} \mathrm{H}-\mathrm{NMR}$ spectra of GelMA and CSMA. (C) Macroscopic and SEM images of the 3D spatial structure of scaffold.

\subsection{Mechanical Properties and Biodegradation of 3D-Printed Hydrogel Scaffolds}

In the present study, four types of scaffolds-made by mixing PEGDA solution $(w / v)$, GelMA $(w / v)$, and CSMA $(w / v)$ - were designed at various mass ratios of 10/15/0, $10 / 14 / 1,10 / 12.5 / 2.5$, and 10/10/5, respectively (Table 2). A compression measurement was performed to assess the compressive stiffness of 3D-printed hydrogel scaffolds in Figure 2A. The elastic modulus was detected by the applied force normalized to the sample cross-sectional area divided by the compressive strain. The results showed that the trend of stress and compressive modulus was consistent (Figure 2A,B). Compared to the PEGDA-GelMA scaffold, the level of stress and compressive modulus was significantly higher in the PEGDA10-GelMA12.5-CSMA2.5 and PEGDA10-GelMA10-CSMA5 scaffolds $(n=3, p<0.01)$. 
Table 2. Composition and notation of 3D scaffolds tested in this study.

\begin{tabular}{cc}
\hline Composition (wt. \%) & Notation \\
\hline 10\% PEGDA, 15\% GelMA & PEGDA10-GelMA15 \\
10\% PEGDA, 14\% GelMA, 1\% CSMA & PEGDA10-GelMA14-CSMA1 \\
10\% PEGDA, 12.5\% GelMA, 2.5\% CSMA & PEGDA10-GelMA12.5-CSMA2.5 \\
10\% PEGDA, 10\% GelMA, 5\% CSMA & PEGDA10-GelMA10-CSMA5 \\
\hline
\end{tabular}
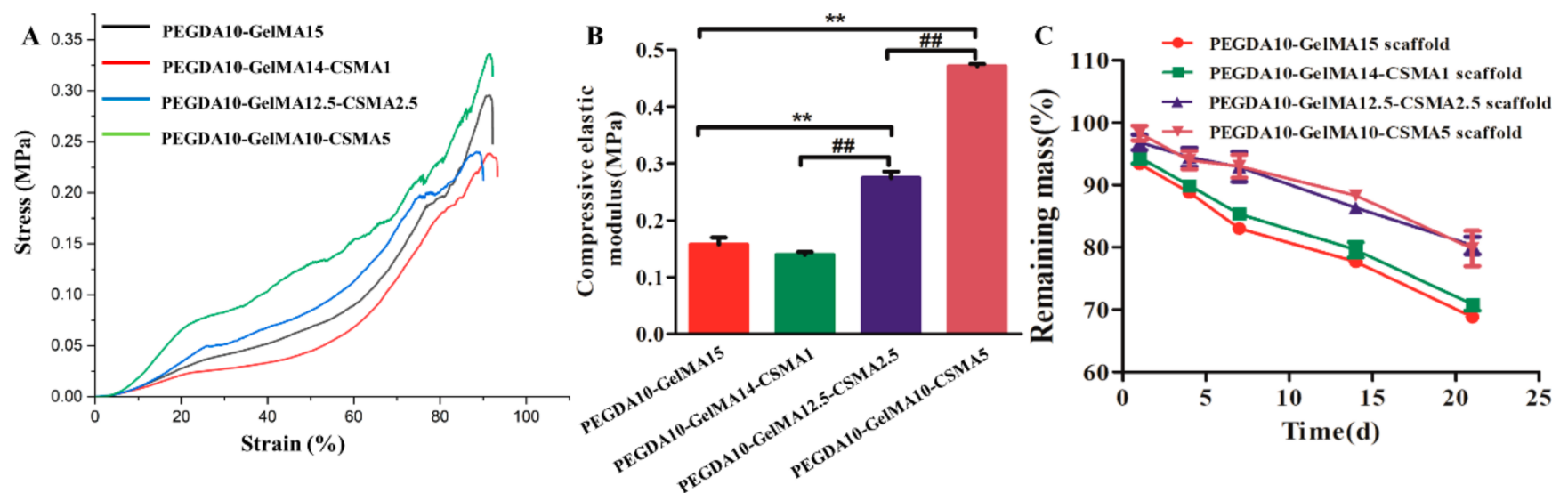

Figure 2. The mechanical properties and biodegradation of 3D-printed hydrogel scaffolds. (A) Stress-strain curves. (B) Compressive elastic modulus $\left(n=3,{ }^{* *} p<0.01,{ }^{\# \#} p<0.01\right)$. (C) In vitro degradation of scaffolds in protease $\mathrm{K}$ at each time point $(n=5)$.

The biodegradation of scaffolds was tested in protease $\mathrm{K}$ at $37^{\circ} \mathrm{C}$ (Figure $2 \mathrm{C}$ ). The incorporation of CSMA into the scaffolds increased the cross-linked density and internal structural compactness. Therefore, the scaffolds containing CSMA exhibited a slower degradation rate than the hydrogels without CSMA. After the incubation of 21 days, the remaining masses were $68.82 \pm 0.67 \%$ for PEGDA10-GelMA15 scaffold, $70.84 \pm 0.99 \%$ for PEGDA10-GelMA14-CSMA1 scaffold, $80.30 \pm 1.40 \%$ for PEGDA10-GelMA12.5-CSMA2.5 scaffold, and $79.80 \pm 2.83 \%$ for PEGDA10-GelMA10-CSMA5 scaffold. The incorporation of CSMA was useful to maintain the structural stability of hydrogel scaffolds. Structurally stable hydrogels would be beneficial to the proliferation, adhesion, and ECM production of cells.

\subsection{Cytocompatibility of 3D-Printed Scaffolds}

The Live/Dead assay suggested that most of the seeded cells (95\%) survived on the scaffolds, with only a few dead cells found after $72 \mathrm{~h}$ of culture in the growth medium (Figure 3A). These results showed the low cytotoxicity of four biocompatible hydrogel scaffolds. After seven days of culture, the viability of BMSCs in the PEGDA-GelMA scaffold was similar to that of PEGDA-GelMA-CSMA scaffolds $(n=3, p>0.05)$ (Figure 3B). The cytoskeleton staining was carried out to show the morphology of BMSCs in tested scaffolds after culturing for $72 \mathrm{~h}$ as shown in Figure 3C. The mean fluorescence intensity indicated that the expression of F-actin of BMSCs was significantly upregulated with the increasing content of CSMA ( $n=3, p<0.05)$ (Figure 3D). Therefore, the CCK-8 assay indicated the proliferation of BMSCs on the four groups of scaffolds had no statistical difference among them at day $1,3,5$, and $7(n=5, p>0.05)$ (Figure $3 \mathrm{E})$. 

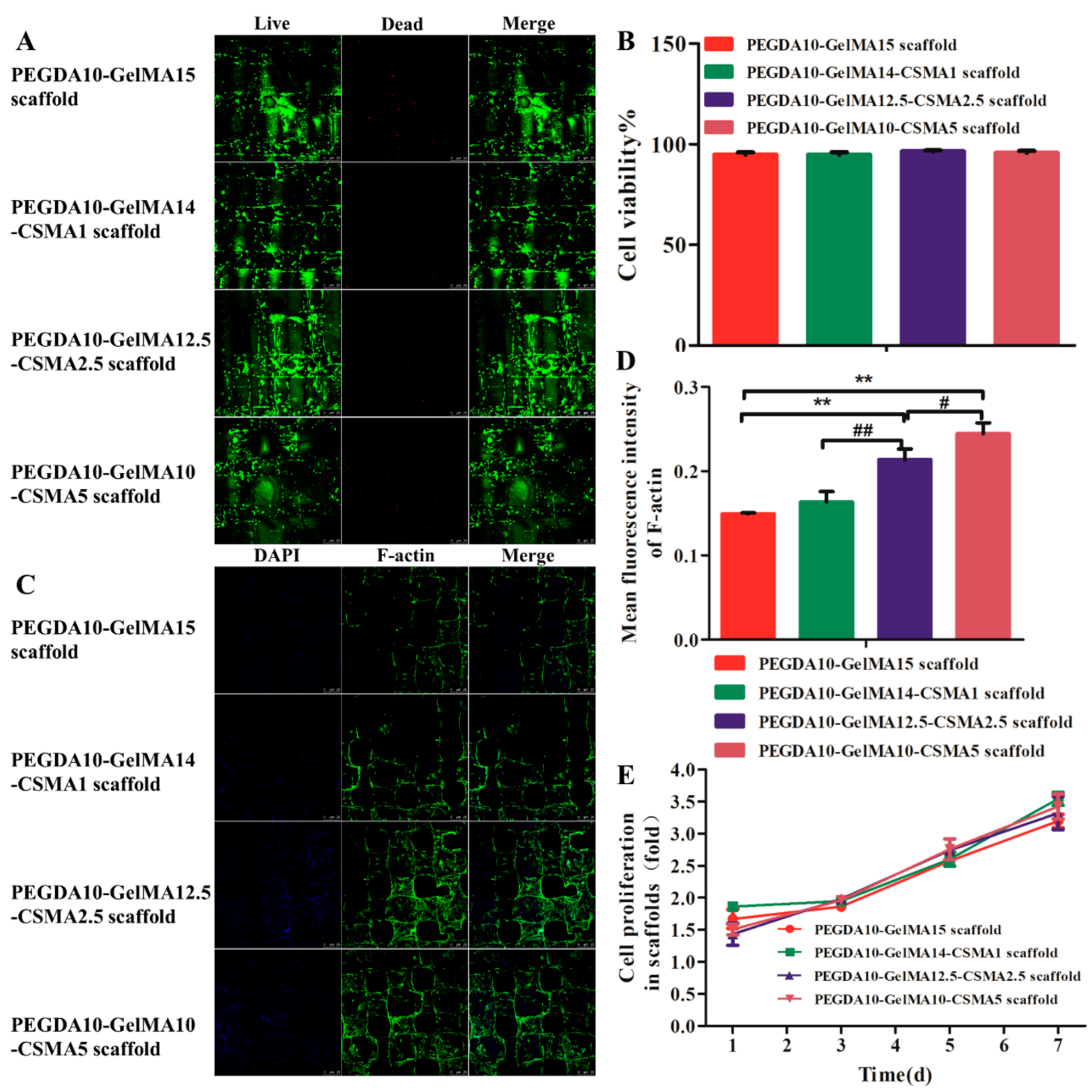

Figure 3. The cytocompatibility of 3D-printed scaffolds. (A) Live/dead staining images. (B) Percentage of live cells detected by Live/Dead staining. The live cells are indicated by green staining, while dead cells are shown as red. (C) Cytoskeletal staining images. (D) mean fluorescence intensity of F-actin. (E) CCK-8 assay. The scale bar is $25 \mu \mathrm{m}(n=3$; ** $p<0.01$, \#\# $\left.p<0.01,{ }^{\#} p<0.05\right)$.

\subsection{RT-PCR Analysis}

The effect of CSMA on chondrogenic differentiation of BMSCs on the scaffolds was investigated by evaluating the expression of cartilage-specific genes, including COL-2, SOX-9, ACAN, and PRG4 at mRNA level as shown in Figure 4A. We analyzed the expression of osteogenesis marker gene ALP and COL-1 and hypertrophic gene COL-10 (Figure 4B,C). Compared to the PEGDA-GelMA scaffold, the expression of COL-2, SOX-9, ACAN, and PRG4 were significantly upregulated, while the expression of ALP and COL-1 were significantly downregulated in the PEGDA-GelMA-CSMA scaffolds after incubation for 7 and 14 days $(n=3, p<0.05)$. There was no significant difference in the expression of COL-10 in the tested groups $(n=3, p>0.05)$, suggesting that four scaffolds could support cell growth and prevent cell aging. These results showed that the expression of COL-2, SOX-9, ACAN, and PRG4 and osteogenesis marker genes (ALP and COL-1) changed significantly with the increasing concentration of CSMA in the indicated scaffolds. 

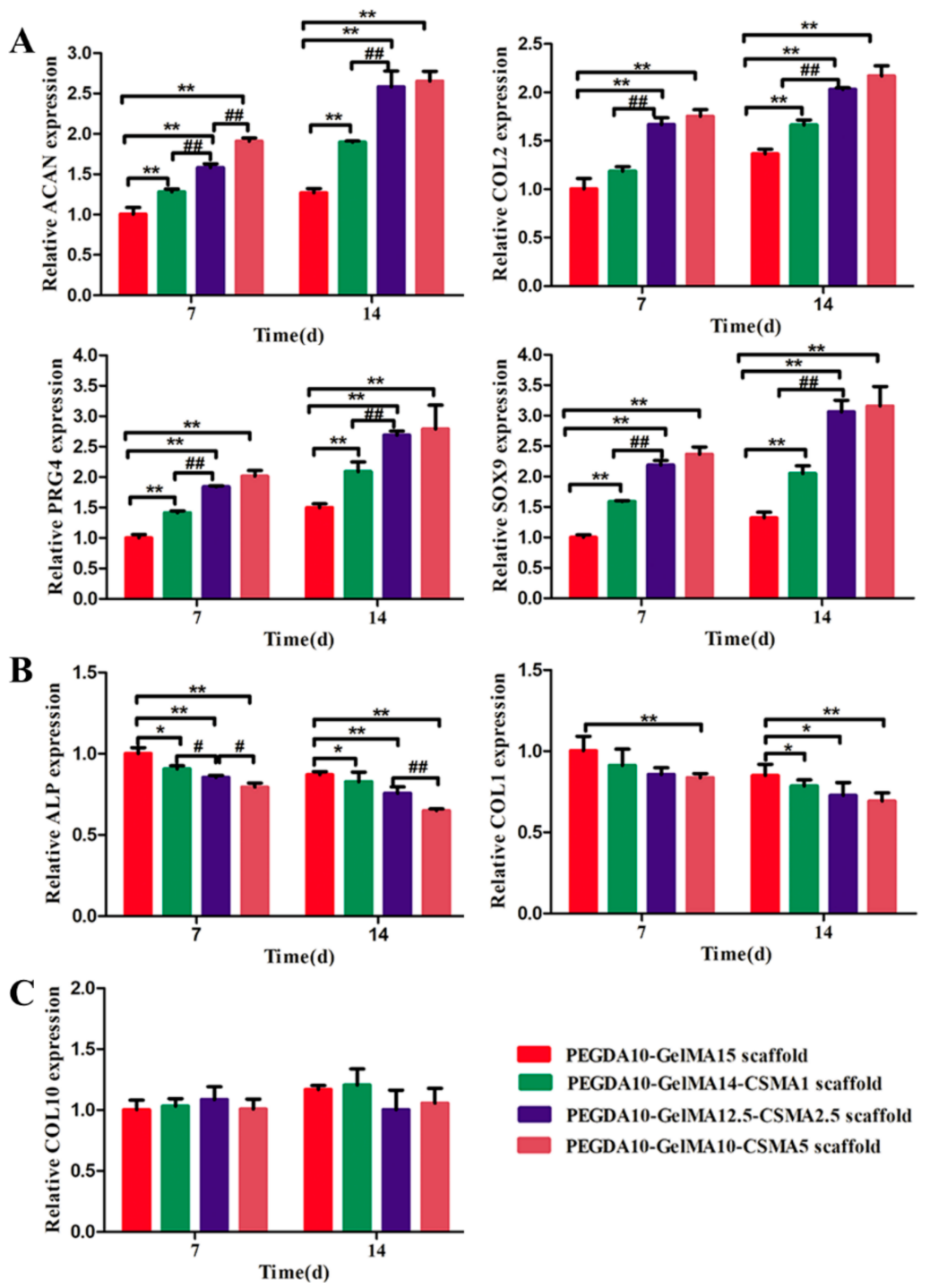

Figure 4. RT-PCR analysis. (A) The expression of cartilage-specific genes (ACAN, COL2, SOX9, and PRG4) and (B) osteogenesis marker gene (ALP and COL-1). (C) hypertrophic gene COL-10 of BMSCs within various scaffolds determined by RT-PCR tests on day 7 and $14\left(n=3{ }^{*} p<0.05,{ }^{\#} p<0.05\right.$, ** $\left.p<0.01,{ }^{\# \#} p<0.01\right)$.

\subsection{COL 2, ACAN, and SOX 9 Production Analysis by Immunofluorescence}

BMSCs are an essential and multipotent form of stem cell which can undergo osteogenic, chondrogenic, and adipogenic differentiation under specific conditions. In the present study, the chondrogenic differentiation was induced on four types of scaffolds for two weeks. The expression profiles of the cartilage-specific markers (COL2, ACAN, and SOX9) were evaluated by immunofluorescence staining. Figures 5 and 6 showed that after 14 days of culture, the expression of COL2, ACAN, and SOX9 was significantly increased in the PEGDA-GelMA-CSMA scaffolds compared to the PEGDA-GelMA scaffold. These results indicate that the addition of CSMA to the scaffolds could remarkably enhance the chondrogenic differentiation of BMSCs. 


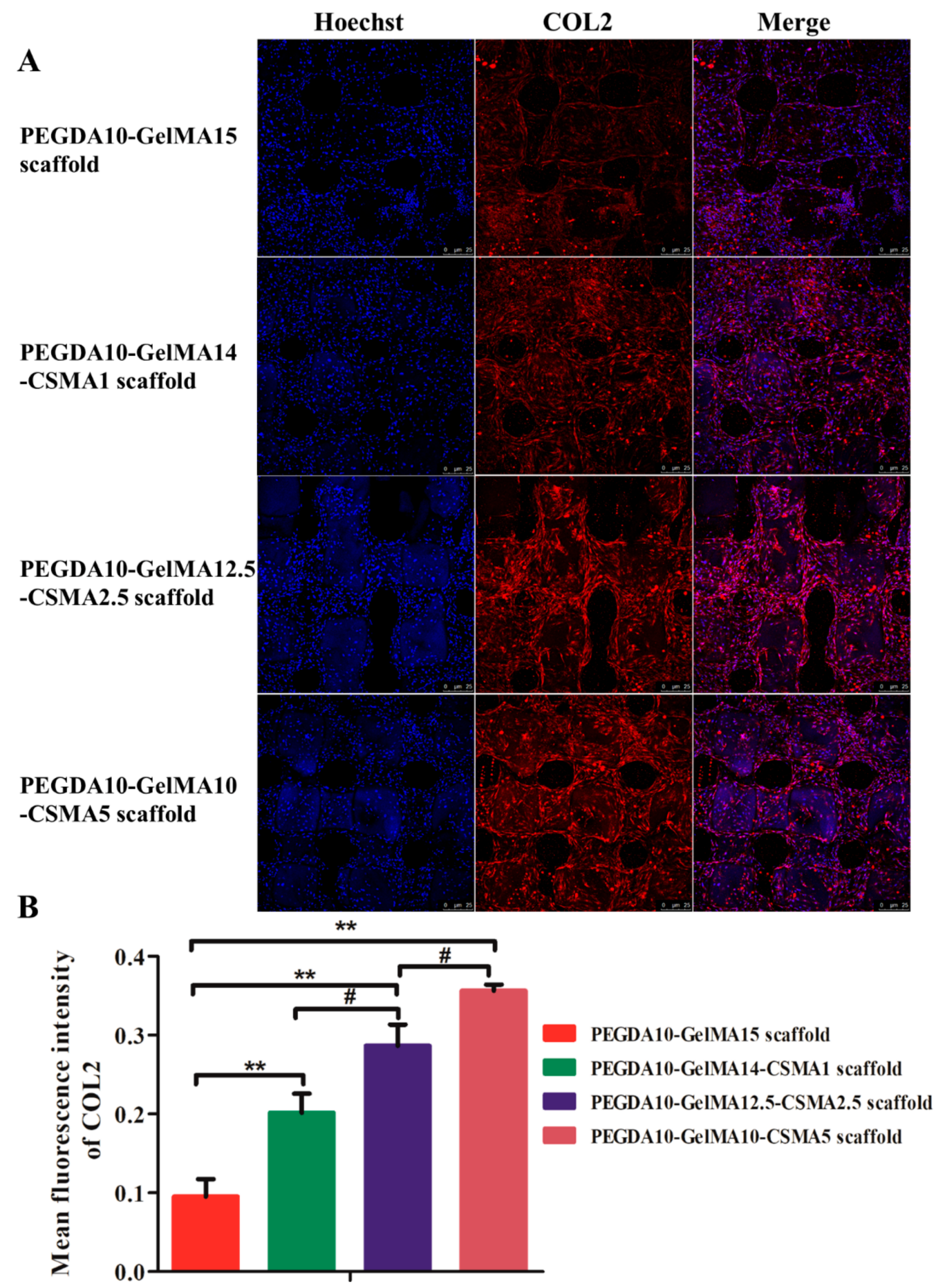

Figure 5. Immunofluorescent staining of COL2 on the scaffolds seeded with BMSCs. (A) Immunofluorescence staining images and (B) mean fluorescence intensity of COL2 secreted by BMSCs on four scaffolds on day 14. The nuclei are stained blue while the protein COL2 is stained red. The scale bar is $25 \mu \mathrm{m}\left(n=3 ;{ }^{* *} p<0.01,{ }^{\#} p<0.05\right)$. 


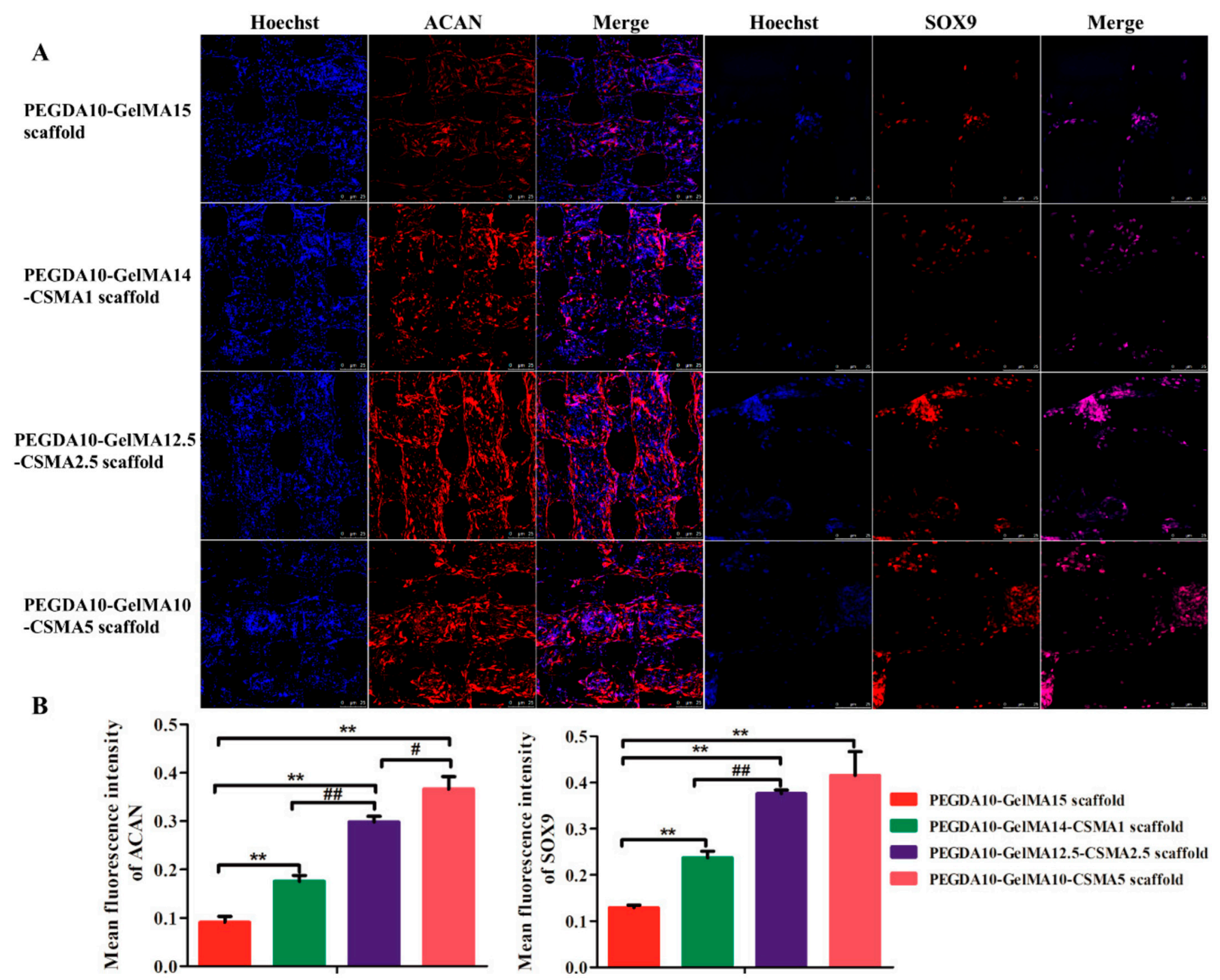

Figure 6. ACAN and SOX9 production analysis by immunofluorescence. (A) Immunofluorescence staining images and (B) fluorescence intensity of ACAN and SOX9 secreted by BMSCs on four scaffolds on day 14 . The nuclei are stained blue. The proteins ACAN and SOX9 are stained red. The scale bar is $25 \mu \mathrm{m}\left(n=3 ;{ }^{* *} p<0.01,{ }^{\# \#} p<0.01,{ }^{\#} p<0.05\right)$.

\subsection{ECM Deposition on Scaffolds}

The DNA contents of four cell-hydrogel composites increased over time. The average DNA content in groups of PEGDA-GelMA-CSMA scaffolds was higher than the PEGDAGelMA scaffold, but no statistical difference was noted among the tested groups $(n=3$, $p>0.05$ ) (Figure 7A). On days 14 and 21, a significantly higher GAG content was found in the PEGDA-GelMA-CSMA scaffold groups than in the PEGDA-GelMA group (Figure 7B). In addition, COL-2 content in four hydrogel scaffolds was quantitatively detected for 3 weeks culture by ELISA kit (Figure 7C). The content of COL2 in tested scaffold groups was significantly increased after incubation of 21 days, which was consistent with the GAG production trend detected by the DMMB $(p<0.01)$. The fraction of total GAGs was influenced by the presence of CSMA. GAG was an essential ECM component in articular cartilage, and its production was directly correlated with the level of chondrogenesis. Therefore, these results suggested that the addition of CSMA to the scaffold could remarkably enhance the chondrogenic differentiation of BMSCs. 

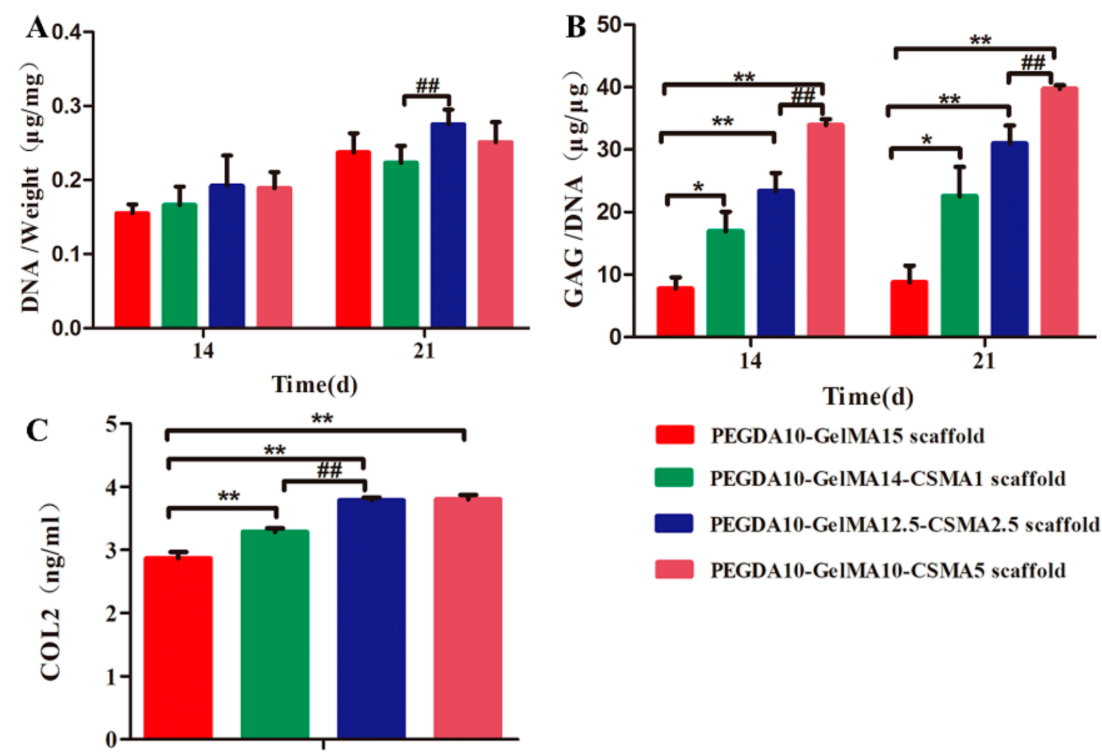

Figure 7. DNA contents, GAG production, and COL2 proteins in different types of PEGDA-GelMACSMA scaffolds on day 14 and day 21 culture. (A) DNA contents, (B) GAG production, and (C) COL2 deposition on four scaffolds by the BMSCs $\left(n=3\right.$; $\left.^{*} p<0.05,{ }^{* *} p<0.01,{ }^{\# \#} p<0.01\right)$.

\section{Discussion}

Tissue engineering is considered for obtaining tissue reconstruction through biomaterials and the external seeding of cells. However, considering the time and cost of harvesting, proliferation, and differentiation of cells, a cell-free scaffold-based strategy could be of high clinical value for tissue regeneration and repair [23-26]. Currently, 3D printing technologies are receiving immense consideration for the fabrication of tissue scaffolds with well-defined microarchitecture for specific applications. Some 3D printing technologies allow cell-loaded printing, which can facilitate tissue regeneration by significantly enhancing the interaction between the cells and scaffold matrix. Similarly, the hydrogels as the substrate with direct contact with the cells (in vitro) and tissues (in vivo) should be biocompatible, non-toxic, and biodegradable in the formulation of bio-ink. To date, 3D bioprinting of scaffolds has been achieved for different applications, especially for cartilage regeneration $[27,28]$. The hydrogel-based bio-inks could be used as a suitable scaffold material for cartilage regeneration because of their structural similarity to ECM, high water retention, and biocompatibility $[29,30]$. Considering the abundance of CS as GAGs in cartilage ECM, it was added into the hydrogels to obtain the scaffolds with a biomimetic environment for enhancing chondrogenesis [31]. In addition, GelMA was also a biocompatible agent with photocrosslinking ability to be widely applied in cell-laden bioprinting [32]. To improve the hydrogel scaffolds with high mechanical strength, CSMA and GelMA with a high content of double bond were synthesized for the structural crosslinking (Figure 1). 3D printing can accurately determine the external and internal pore structure of the scaffold. In this study, the 3D printing technique was employed for the fabrication of a hydrogel cartilage construct by mixing PEGDA, GelMA, and CSMA. Accurate control of internal pore size is another key requirement of porous scaffold [33]. In macroporous scaffolds, porosity can guide tissue regeneration by regulating vascularization [34]. The reports suggest that the optimal pore size of the scaffolds ranges from 100 to $400 \mu \mathrm{m}$ [35-37]. In the present study, PEGDA-GelMA and PEGDA-GelMA-CSMA scaffolds provided a uniform pore size of $200 \mu \mathrm{m}$ (Figure 1C). Besides, sufficient interconnectivity of porous hydrogel scaffolds is also important for nutrient uptake, exchange of gases, cell migration, and cell-cell interaction, which is crucial for chondrogenesis.

The scaffold with suitable mechanical properties mimicking the native tissues is one critical 3D scaffold design criterion. Although CSMA and GelMA are highly biocompatible 
materials for cell-laden bioprinting, their mechanical properties and printing resolution greatly limited their application in 3D bioprinting [32]. In the present study, we added CSMA into the PEGDA-GelMA hydrogels, which greatly enhanced the compressive elastic moduli in PEGDA10-GelMA12.5-CSMA2.5 and PEGDA10-GelMA10-CSMA5 scaffolds compared to the pure PEGDA-GelMA (Figure 2A).

Some GelMA hydrogels were reported to degrade in a few hours in vitro [38-40], while others remain stable even up to 10 days [41]. The degradation experiments lasted for several weeks when no enzyme was added to the system $[42,43]$. It was reported that cell-secreted ECM and the hydrogels were sensitive to enzymatic degradation reaction $[44,45]$. Thus, the mechanical properties of the constructs were associated with the balance between anabolic and catabolic factors combined with hydrolytic degradation. The biodegradation tests performed in the solution of proteinase $\mathrm{K}$ indicated that there was no significant change in the biodegradation rate among the tested scaffolds (Figure 2). Therefore, the results of biodegradation were consistent with the uniform porous structure of the 3D-printed PEGDA-GelMA-CSMA porous scaffold. The biodegradation was closely related to the specific surface area and a surface-erosion mechanism was noted on enzymatic degradation. Due to the kinetics of hydrogel degradation and tissue growth are closely related [46,47], further study should be conducted to investigate the role of scaffold degradation and remodeling rates in assessing the performance of 3D-printed hydrogel scaffolds.

On account of the unique biological characteristics of stem cells, many reports have confirmed the great application prospect of stem cells in tissue engineering [32,48]. After successful fabrication of optimized scaffolds, the functional modification of marrow stem cells (MSC) homing ability was conducted for the regeneration ability and forming complex tissues [49-51]. However, the main reason hindering the effective translation of MSC homing therapy was that specific cells cannot be effectively selected to defect tissue [49]. In the present study, it was noted that the conjugating procedure had no influence on the bioactivity of BMSCs, and no cytotoxic compounds were produced, as evidenced by the cell viability and morphological alteration (Figure 3). Additionally, the fluorescent images of cells showed that BMSCs could maintain similar shapes in each specific PEGDA-GelMA-CSMA scaffolds (Figure 3). The images suggest chondrocyte-like round morphology after incubation in a chondrogenic induced culture medium (Figures 5 and 6). The mean fluorescence intensity of F-actin indicated that the expression of F-actin was significantly upregulated with the increased amounts of CSMA, because CSMA could provide a biomimetic environment like the ECM of cartilage. Therefore, our findings demonstrated that the CSMA matrix in the PEGDA-GelMA-CSMA scaffolds could provide an environment for cell adhesion, proliferation, and differentiation.

In 3D-printed PEGDA-GelMA-CSMA scaffolds, the main chondrogenic marker of COL2 was upregulated in the RT-PCR and immunofluorescence tests (Figures 4 and 5), whereas the main osteogenic marker genes, COL1 and ALP were downregulated compared to the PEGDA-GelMA scaffolds (Figure 4). The BMSCs on the PEGDA-GelMA scaffolds took on an elongated shape like fibroblasts, while the round chondrocyte-like cells on the PEGDA-GelMA-CSMA scaffold led to the decreased expression of osteogenesis markers of COL1 and ALP. This finding was consistent with a previous study, which illustrated that cell morphology was associated with cell differentiation [1]. The in vitro result was particularly relevant to clinical practices [51]. The incorporation of CSMA to the scaffolds resulted in increased accumulation of cartilage matrix molecules and increased compressive modulus. The expression of cartilage-specific genes (COL2, ACAN, SOX9, and PRG4) (Figure 4) and GAG/DNA ratio were higher in constructs containing CSMA (Figure 7), indicating that CSMA promoted biosynthesis of cartilage-specific matrix molecules.

Mechanical strength is an important metric to determine the quality of tissue cartilage. Studies have shown that the cartilage from bovine femoral condyles has Young's modulus of approximately 0.3 $\mathrm{MPa}$ [52], and GAGs have a significant effect on the compression stiffness of the tissue through water absorption [53]. In this study, the high GAG level fully accounted for changes in the mechanical properties. The reason for the discrepancy in 
GAG content and construct modulus may be the favorable effect of PEGDA-GelMA-CSMA scaffolds: i.e., enhancing the matrix distribution. Additionally, the collagen network also facilitated improvement in the stiffness of the constructs. The significantly increased level of COL2 was induced by the CSMA hydrogel, indicating that CSMA enhanced the distribution of COL2 and ACAN. As a result, the mechanical properties were improved remarkably. The newly synthesized constructs containing CSMA should be more interconnected to exhibit greater mechanical reinforcement. The mechanisms by which CSMA enhances the distribution of new matrix and improves its mechanical properties are still not fully clear and warrant further investigation.

\section{Conclusions}

In summary, we prepared a novel class of 3D-printed PEGDA-GelMA-CSMA scaffolds for cartilage tissue regeneration. The findings showed that the higher content of CSMA possessed higher compressive modulus and slower degradation. The cell viability indicated these hydrogel scaffolds were non-toxic with good cytocompatibility. Cytoskeleton staining, immunofluorescence staining, and RT-PCR test verified that the PEGDA-GelMACSMA scaffolds could decrease the expression of osteogenic marker genes and enhance the expression of cartilage-specific genes as well as matrix deposition of the increased level of GAG. These customizable 3D-printed PEGDA-GelMA-CSMA scaffolds pave a new pathway for acquiring intelligent biomaterials for applications in cartilage tissue engineering.

Author Contributions: J.G. and F.-z.Y. contributed equally to this study: conceptualization, methodology, investigation, formal analysis, data curation, writing — original draft preparation; Z.-m.M.: visualization; H.-1.Z.: software, resources.; L.L.: validation, supervision, project administration; H.H.C. and J.-k.Y.: conceptualization, writing-review and editing, funding acquisition. All authors have read and agreed to the published version of the manuscript.

Funding: This work was supported by the National Natural Science Foundation of China (NO. 51773004).

Institutional Review Board Statement: The animal study was reviewed and approved by Animal Care and Use Committee of Peking University Third Hospital.

Informed Consent Statement: Not applicable.

Data Availability Statement: All datasets generated for this study are included in the article.

Conflicts of Interest: The authors declare no conflict of financial interest.

\section{References}

1. Huey, D.J.; Hu, J.; Athanasiou, K.A. Unlike Bone, Cartilage Regeneration Remains Elusive. Science 2012, 338, 917-921. [CrossRef] [PubMed]

2. Chen, Y.-R.; Zhou, Z.-X.; Zhang, J.-Y.; Yuan, F.-Z.; Xu, B.-B.; Guan, J.; Han, C.; Jiang, D.; Yang, Y.; Yu, J.-K. Low-Molecular-Weight Heparin-Functionalized Chitosan-Chondroitin Sulfate Hydrogels for Controlled Release of TGF- $\beta 3$ and in vitro Neocartilage Formation. Front. Chem. 2019, 7, 745. [CrossRef]

3. Wang, S.-J.; Zhang, Z.-Z.; Jiang, D.; Qi, Y.-S.; Wang, H.-J.; Zhang, J.-Y.; Ding, J.-X.; Yu, J.-K. Thermogel-coated Poly(epsiloncaprolactone) composite scaffold for enhanced cartilage tissue engineering. Polymers 2016, 8, 200. [CrossRef]

4. Izadifar, Z.; Chen, X.; Kulyk, W. Strategic Design and Fabrication of Engineered Scaffolds for Articular Cartilage Repair. J. Funct. Biomater. 2012, 3, 799-838. [CrossRef]

5. Armiento, A.; Stoddart, M.; Alini, M.; Eglin, D. Biomaterials for articular cartilage tissue engineering: Learning from biology. Acta Biomater. 2018, 65, 1-20. [CrossRef]

6. Yang, J.; Zhang, Y.S.; Yue, K.; Khademhosseini, A. Cell-laden hydrogels for osteochondral and cartilage tissue engineering. Acta Biomater. 2017, 57, 1-25. [CrossRef]

7. Naahidi, S.; Jafari, M.; Logan, M.; Wang, Y.; Yuan, Y.; Bae, H.; Dixon, B.; Chen, P. Biocompatibility of hydrogel-based scaffolds for tissue engineering applications. Biotechnol. Adv. 2017, 35, 530-544. [CrossRef] [PubMed]

8. Talaat, W.; Aryal, A.C.S.; Al Kawas, S.; Samsudin, A.B.R.; Kandile, N.G.; Harding, D.R.K.; Ghoneim, M.M.; Zeiada, W.; Jagal, J.; Aboelnaga, A.; et al. Nanoscale Thermosensitive Hydrogel Scaffolds Promote the Chondrogenic Differentiation of Dental Pulp Stem and Progenitor Cells: A Minimally Invasive Approach for Cartilage Regeneration. Int. J. Nanomed. 2020, 15, 7775-7789. [CrossRef] [PubMed] 
9. Sun, K.; Li, R.; Jiang, W.; Sun, Y.; Li, H. Comparison of three-dimensional printing and vacuum freeze-dried techniques for fabricating composite scaffolds. Biochem. Biophys. Res. Commun. 2016, 477, 1085-1091. [CrossRef]

10. Shi, W.; Sun, M.; Hu, X.; Ren, B.; Cheng, J.; Li, C.; Duan, X.; Fu, X.; Zhang, J.; Chen, H.; et al. Structurally and Functionally Optimized Silk-Fibroin-Gelatin Scaffold Using 3D Printing to Repair Cartilage Injury In Vitro and In Vivo. Adv. Mater. 2017, 29, 1701089. [CrossRef]

11. Daly, A.; Freeman, F.; Gonzalez-Fernandez, T.; Critchley, S.E.; Nulty, J.; Kelly, D.J. 3D Bioprinting for Cartilage and Osteochondral Tissue Engineering. Adv. Healthc. Mater. 2017, 6, 1700298. [CrossRef]

12. Dhandayuthapani, B.; Yoshida, Y.; Maekawa, T.; Kumar, S. Polymeric Scaffolds in Tissue Engineering Application: A Review. Int. J. Polym. Sci. 2011, 2011, 1-19. [CrossRef]

13. Gao, J.; Ding, X.; Yu, X.; Chen, X.; Zhang, X.; Cui, S.; Shi, J.; Chen, J.; Yu, L.; Chen, S.; et al. Cell-Free Bilayered Porous Scaffolds for Osteochondral Regeneration Fabricated by Continuous 3D-Printing Using Nascent Physical Hydrogel as Ink. Adv. Healthc. Mater. 2021, 10, e2001404. [CrossRef]

14. Abbadessa, A.; Blokzijl, M.; Mouser, V.; Marica, P.; Malda, J.; Hennink, W.; Vermonden, T. A thermo-responsive and photopolymerizable chondroitin sulfate-based hydrogel for 3D printing applications. Carbohydr. Polym. 2016, 149, 163-174. [CrossRef] [PubMed]

15. Strehin, I.; Nahas, Z.; Arora, K.; Nguyen, T.; Elisseeff, J. A versatile pH sensitive chondroitin sulfate-PEG tissue adhesive and hydrogel. Biomaterials 2010, 31, 2788-2797. [CrossRef]

16. Hong, S.; Sycks, D.; Chan, H.F.; Lin, S.; Lopez, G.P.; Guilak, F.; Leong, K.W.; Zhao, X. 3D Printing of Highly Stretchable and Tough Hydrogels into Complex, Cellularized Structures. Adv. Mater. 2015, 27, 4035-4040. [CrossRef]

17. Sun, M.; Sun, X.; Wang, Z.; Guo, S.; Yu, G.; Yang, H. Synthesis and Properties of Gelatin Methacryloyl (GelMA) Hydrogels and Their Recent Applications in Load-Bearing Tissue. Polymers 2018, 10, 1290. [CrossRef] [PubMed]

18. Liu, J.; Li, L.; Suo, H.; Yan, M.; Yin, J.; Fu, J. 3D printing of biomimetic multi-layered GelMA/nHA scaffold for osteochondral defect repair. Mater. Des. 2019, 171, 107708. [CrossRef]

19. Guo, Y.; Yuan, T.; Xiao, Z.; Tang, P.; Xiao, Y.; Fan, Y.; Zhang, X. Hydrogels of collagen/chondroitin sulfate/hyaluronan interpenetrating polymer network for cartilage tissue engineering. J. Mater. Sci. Mater. Med. 2012, 23, 2267-2279. [CrossRef]

20. Zhu, M.; Wang, Y.; Ferracci, G.; Zheng, J.; Cho, N.-J.; Lee, B.H. Gelatin methacryloyl and its hydrogels with an exceptional degree of controllability and batch-to-batch consistency. Sci. Rep. 2019, 9, 1-13. [CrossRef]

21. Wang, L.F.; Shen, S.-S.; Lu, S.-C. Synthesis and characterization of chondroitin sulfate-methacrylate hydrogels. Carbohydr. Polym. 2003, 52, 389-396. [CrossRef]

22. Zhang, Z.-Z.; Jiang, D.; Wang, S.-J.; Qi, Y.-S.; Zhang, J.-Y.; Yu, J.-K. Potential of Centrifugal Seeding Method in Improving Cells Distribution and Proliferation on Demineralized Cancellous Bone Scaffolds for Tissue-Engineered Meniscus. ACS Appl. Mater. Interfaces 2015, 7, 15294-15302. [CrossRef] [PubMed]

23. Makris, E.A.; Gomoll, A.H.; Malizos, K.N.; Hu, J.C.; Athanasiou, K.A. Repair and tissue engineering techniques for articular cartilage. Nat. Rev. Rheumatol. 2015, 11, 21-34. [CrossRef] [PubMed]

24. Liang, X.; Duan, P.; Gao, J.; Qu, Z.; Li, X.; He, Y.; Yao, H.; Ding, J. Bilayered PLGA/PLGA-HAp composite scaffold for osteochondral tissue engineering and tissue regeneration. ACS Biomater. Sci. Eng. 2018, 4, 3506-3521. [CrossRef]

25. Li, L.; Li, J.; Guo, J.; Zhang, H.; Zhang, X.; Yin, C.; Wang, L.; Zhu, Y.; Yao, Q. 3D Molecularly Functionalized Cell-Free Biomimetic Scaffolds for Osteochondral Regeneration. Adv. Funct. Mater. 2019, 29, 1807356. [CrossRef]

26. Zhou, Z.; Wu, W.; Fang, J.; Yin, J. Polymer-based porous microcarriers as cell delivery systems for applications in bone and cartilage tissue engineering. Int. Mater. Rev. 2021, 66, 77-113. [CrossRef]

27. Markstedt, K.; Mantas, A.; Tournier, I.; Ávila, H.M.; Hägg, D.; Gatenholm, P. 3D Bioprinting Human Chondrocytes with Nanocellulose-Alginate Bioink for Cartilage Tissue Engineering Applications. Biomacromolecules 2015, 16, 1489-1496. [CrossRef]

28. Weigelt, B.; Bissell, M.J. Unraveling the microenvironmental influences on the normal mammary gland and breast cancer. Semin. Cancer Biol. 2008, 18, 311-321. [CrossRef]

29. Cui, H.; Nowicki, M.; Fisher, J.P.; Zhang, L.G. 3D Bioprinting for Organ Regeneration. Adv. Healthc. Mater. 2017, 6, 27995751. [CrossRef]

30. Stanton, M.; Samitier, J.; Sánchez, S. Bioprinting of 3D hydrogels. Lab A Chip 2015, 15, 3111-3115. [CrossRef]

31. Spiller, K.L.; Maher, S.A.; Lowman, A.M. Hydrogels for the repair of articular cartilage defects. Tissue Eng. Part. B Rev. 2011, 17, 281-299. [CrossRef]

32. Zhu, W.; Cui, H.; Boualam, B.; Masood, F.; Flynn, E.; Rao, R.D.; Zhang, Z.-Y.; Zhang, L.G. 3D bioprinting mesenchymal stem cell-laden construct with core-shell nanospheres for cartilage tissue engineering. Nanotechnology 2018, 29, 185101. [CrossRef]

33. Liang, X.; Gao, J.; Xu, W.; Wang, X.; Shen, Y.; Tang, J.; Cui, S.; Yang, X.; Liu, Q.; Yu, L.; et al. Structural mechanics of 3D-printed poly(lactic acid) scaffolds with tetragonal, hexagonal and wheel-like designs. Biofabrication 2019, 11, 0350090. [CrossRef] [PubMed]

34. Gupte, M.J.; Swanson, W.B.; Hu, J.; Jin, X.; Ma, H.; Zhang, Z.; Liu, Z.; Feng, K.; Feng, G.; Xiao, G.; et al. Pore size directs bone marrow stromal cell fate and tissue regeneration in nanofibrous macroporous scaffolds by mediating vascularization. Acta Biomater. 2018, 82, 1-11. [CrossRef] [PubMed]

35. Duan, P.; Pan, Z.; Cao, L.; He, Y.; Wang, H.; Qu, Z.; Dong, J.; Ding, J. The effects of pore size in bilayered poly(lactide-co-glycolide) scaffolds on restoring osteochondral defects in rabbits. J. Biomed. Mater. Res. Part. A 2014, 102, 180-192. [CrossRef] 
36. Pan, Z.; Duan, P.; Liu, X.; Wang, H.; Cao, L.; He, Y.; Dong, J.; Ding, J. Effect of porosities of bilayered porous scaffolds on spontaneous osteochondral repair in cartilage tissue engineering. Regen. Biomater. 2015, 2, 9-19. [CrossRef]

37. Zustiak, S.P.; Leach, J.B. Hydrolytically Degradable Poly(Ethylene Glycol) Hydrogel Scaffolds with Tunable Degradation and Mechanical Properties. Biomacromolecules 2010, 11, 1348-1357. [CrossRef]

38. Chen, Y.-C.; Lin, R.-Z.; Qi, H.; Yang, Y.; Bae, H.; Melero-Martin, J.M.; Khademhosseini, A. Functional human vascular network generated in photocrosslinkable gelatin methacrylate hydrogels. Adv. Funct. Mater. 2012, 22, 2027-2039. [CrossRef]

39. Ovsianikov, A.; Deiwick, A.; Van Vlierberghe, S.; Dubruel, P.; Moöller, L.; Draäger, G.; Chichkov, B. Laser Fabrication of ThreeDimensional CAD Scaffolds from Photosensitive Gelatin for Applications in Tissue Engineering. Biomacromolecules 2011, 12, 851-858. [CrossRef]

40. Gao, F.; Xu, Z.; Liang, Q.; Li, H.; Peng, L.; Wu, M.; Zhao, X.; Cui, X.; Ruan, C.; Liu, W. Osteochondral regeneration with 3D-printed biodegradable high-strength supramolecular polymer reinforced-gelatin hydrogel scaffolds. Adv. Sci. 2019, 6, 1900867. [CrossRef] [PubMed]

41. Koshy, S.T.; Ferrante, T.C.; Lewin, S.A.; Mooney, D.J. Injectable, porous, and cell-responsive gelatin cryogels. Biomaterials 2014, 35, 2477-2487. [CrossRef]

42. Li, Z.; Huang, S.; Liu, Y.; Yao, B.; Hu, T.; Shi, H.; Xie, J.; Fu, X. Tuning Alginate-Gelatin Bioink Properties by Varying Solvent and Their Impact on Stem Cell Behavior. Sci. Rep. 2018, 8, 1-8. [CrossRef] [PubMed]

43. Xia, H.; Zhao, D.; Zhu, H.; Hua, Y.; Xiao, K.; Xu, Y.; Liu, Y.; Chen, W.; Liu, Y.; Zhang, W.; et al. Lyophilized Scaffolds Fabricated from 3D-Printed Photocurable Natural Hydrogel for Cartilage Regeneration. ACS Appl. Mater. Interfaces 2018, 10, 31704-31715. [CrossRef] [PubMed]

44. Camci-Unal, G.; Cuttica, D.; Annabi, N.; Demarchi, D.; Khademhosseini, A. Synthesis and Characterization of Hybrid Hyaluronic Acid-Gelatin Hydrogels. Biomacromolecules 2013, 14, 1085-1092. [CrossRef] [PubMed]

45. Levett, P.A.; Melchels, F.P.; Schrobback, K.; Hutmacher, D.W.; Malda, J.; Klein, T.J. A biomimetic extracellular matrix for cartilage tissue engineering centered on photocurable gelatin, hyaluronic acid and chondroitin sulfate. Acta Biomater. 2014, 10, 214-223. [CrossRef]

46. Lalitha, S.S.; Schneider, M.C.; Chu, S.; Roucy, G.; Bryant, S.J.; Vernerey, F.J. Heterogeneity is key to hydrogel-based cartilage tissue regeneration. Soft Matter 2017, 13, 4841-4855. [CrossRef]

47. Peng, Y.; Liu, Q.-J.; He, T.; Ye, K.; Yao, X.; Ding, J. Degradation rate affords a dynamic cue to regulate stem cells beyond varied matrix stiffness. Biomaterials 2018, 178, 467-480. [CrossRef]

48. Bianco, P.; Robey, P.G. Stem cells in tissue engineering. Nature 2001, 414, 118-121. [CrossRef]

49. Karp, J.M.; Leng, T.G. Mesenchymal stem cell homing: The devil is in the details. Cell Stem Cell 2009, 4, 206-216. [CrossRef]

50. Lee, C.H.; Cook, J.L.; Mendelson, A.; Moioli, E.K.; Yao, H.; Mao, J. Regeneration of the articular surface of the rabbit synovial joint by cell homing: A proof of concept study. Lancet 2010, 376, 440-448. [CrossRef]

51. Brittberg, M. Cell carriers as the next generation of cell therapy for cartilage repair: A review of the matrix-induced au-tologous chondrocyte implantation procedure. Am. J. Sports Med. 2010, 38, 1259-1271. [CrossRef] [PubMed]

52. Korhonen, R.; Laasanen, M.; Töyräs, J.; Rieppo, J.; Hirvonen, J.; Helminen, H.; Jurvelin, J. Comparison of the equilibrium response of articular cartilage in unconfined compression, confined compression and indentation. J. Biomech. 2002, 35, 903-909. [CrossRef]

53. Watanabe, H.; Yamada, Y.; Kimata, K. Roles of Aggrecan, a Large Chondroitin Sulfate Proteoglycan, in Cartilage Structure and Function. J. Biochem. 1998, 124, 687-693. [CrossRef] [PubMed] 